\title{
Vascular Access Complication, CTCAE
}

National Cancer Institute

\section{Source}

National Cancer Institute. Vascular Access Complication, CT CAE. NCI Thesaurus. Code C143929.

A finding of a previously undocumented problem related to the vascular access site. 